\title{
STF E O CONTROLE CONCENTRADO: O DIREITO DE MANIFESTAR E A PARTICIPAÇÃO POPULAR
}

\section{STF AND CONCENTRATE CONTROL: THE MANIFEST OF LAW AND POPULAR PARTICIPATION}

\section{${ }^{1}$ Gualterberg Nogueira De Lima Silva ${ }^{2}$ Jacson Gross}

\section{RESUMO}

A presente pesquisa tem como escopo apresentar à comunidade acadêmica questionamentos sobre os "limites do pensamento" e a participação popular brasileira na concretização dos direitos sociais. Como objetivos específicos, serão perquiridos a Arguição de Descumprimento de Preceito Fundamental ADPF 187 (liberação dos eventos chamados "marcha da maconha", que reuniram manifestantes favoráveis à descriminalização da droga); Apresentação de dois casos emblemáticos do direito comparado (Suprema Corte NorteAmericana) sobre o direito de manifestar; e os matizes quanto às jornadas populares de junho de 2013. Serão apresentadas pesquisas empíricas a fim de levantar o grau de legitimidade dessas manifestações junto à opinião pública.

Palavras-chave: Liberdade de pensamento, Manifestações populares, Poder de polícia, Sociedade

\begin{abstract}
This research has the objective to present the academic community questions about the "limits of thought" and Brazilian popular participation in the realization of social rights. Specific objectives will be ask the "accusation of breach of fundamental precept" ADPF 187, June 2009 (release of events called "marijuana march", which gathered protesters in favor of drug decriminalization); Presentation of two emblematic cases of comparative law (US Supreme Court) on the right to manifest; and hues as the popular manifestations of June 2013. Empirical research will be presented in order to raise the degree of legitimacy of these demonstrations in public opinion.
\end{abstract}

Keywords/Palabras-claves/Mots-clés: Freedom of thought, Police power, Popular manifestations, Society

\footnotetext{
${ }^{1}$ Mestrando em Direito pelo Centro Universitário La Salle - UNILASALLE. Rio Grande do Sul (Brasil) E-mail: gualterberglima@gmail.com

${ }^{2}$ Mestrando em Direito pelo Centro Universitário La Salle - UNISALLE. Rio Grande do Sul (Brasil) E-mail: jacson.gross@gmail.com
} 


\title{
1 INTRODUÇÃO
}

Hodiernamente, um dos fundamentos indispensáveis ao Estado Democrático de Direito $^{1}$ é o exercício da cidadania, aí incluído o direito ao livre pensamento e de reunião. Marshall (1967, p. 71-72) traz a ideia mais conhecida e talvez a que mais contribuiu para a discussão do conceito moderno de cidadania. Segundo o autor, cada dimensão de cidadania está ligada a um tipo de direito: cidadania civil aos direitos civis (direitos necessários à liberdade individual), cidadania política aos direitos políticos (direitos de participação no exercício do poder político) e cidadania social aos direitos sociais (direitos que incluem segurança e bemestar econômico, o direito de compartilhar da riqueza socialmente produzida e o de viver uma vida civilizada segundo padrões sociais condizentes).

Vale lembrar, ainda, que a cidadania, no dizer de Hannah Arendt (2010, p. 8-10), é o direito a ter direitos, ou seja, pressupõe a liberdade, a igualdade, a própria existência e a dignidade humana, e acrescenta a referida autora que:

\begin{abstract}
A participação dos cidadãos no governo, qualquer que seja a forma, só é tida como necessária para a liberdade porque o Estado, que necessariamente precisa dispor de meios de força, precisa ser controlado pelos governados no exercício dessa força. [...]. $\mathrm{O}$ que hoje entendemos por governo constitucional, não importa se de natureza monárquica ou republicana, é, em essência, um governo controlado pelos governados, restringido em suas competências de poder e em sua aplicação da força [...].
\end{abstract}

Destarte, a livre opinião pública é fundamental para o controle do exercício do poder, é tributária da garantia da liberdade de expressão e também do direito à reunião, pelo qual se assegura às pessoas a possibilidade de ingressarem na vida pública e interferirem ativamente nas deliberações políticas, pressionando por uma variante da ação estatal ${ }^{2}$. (BRASIL, 1988). Nesse aspecto, o conceito de cidadania alinha-se à soberania popular, ao exercício dos direitos políticos e ao ditame da dignidade humana.

Em meio a essas reflexões iniciais, o presente artigo tem como escopo verificar os limites do pensamento na cultura constitucional e seu contexto em relação aos novos movimentos sociais. Entende-se nesse artigo como novos movimentos sociais, os movimentos surgidos no final do século XX tendo por objetivos específicos, buscando uma identidade e

\footnotetext{
${ }^{1}$ Art. $1^{\circ}$ A República Federativa do Brasil, formada pela união indissolúvel dos Estados e Municípios e do Distrito Federal, constitui-se em Estado Democrático de Direito e tem como fundamentos: I - a soberania; II - a cidadania; III - a dignidade da pessoa humana; IV - os valores sociais do trabalho e da livre iniciativa; V - o pluralismo político.

${ }^{2}$ Art. 5, inc. XVI da Constituição Federal de 1988.
} 
“os 'novos movimentos sociais' contemporâneos são de longe os que mais mobilizam a maioria das pessoas em torno de preocupações comuns. Muito mais que os 'clássicos' movimentos classistas".

A linha de investigação do presente trabalho terá como marco referencial os fundamentos teóricos e políticos na perspectiva da Suprema Corte Norte-Americana sobre a liberdade de expressão; dos limites do pensamento e direito de manifestar elencados pelo Supremo Tribunal Federal (STF) nos eventos chamados "marcha da maconha" (Arguição de Descumprimento de Preceito Fundamental/ADPF 187 - junho de 2009) que reuniram manifestantes favoráveis à descriminalização da droga (COHEN, 2011); bem como será apresentado os matizes quanto às jornadas populares de junho de 2013.

Assim, pretende-se verificar as relações entre Sociedade e Direito na efetivação e na fragmentação deste diante das inúmeras situações em que a sociedade global se apresenta, com características de pluralismo jurídico (SANTOS, 2007), ou seja, onde o espaço geopolítico vigora (oficialmente ou não) mais de uma ordem jurídica.

\section{PRECEDENTES HISTÓRICOS DO DIREITO CONSTITUCIONAL DE MANIFESTAR JUNTO À SUPREMA CORTE NORTE-AMERICANA: CASO MISSOURI KINIGHTS OF THE KLUX KUX KHAN V. KANSAS CITY E TEXAS V. JOHNSON}

Marco Félix Jobim (2011, p. 107), ao realizar trabalho sobre o entendimento dos termos judiciais estadunidenses, alerta sobre a correta compreensão dos mesmos:

\footnotetext{
É cada vez mais assente no ordenamento jurídico brasileiro a assertiva de que se está modificando o sistema até então consagrado do civil law para o sistema da common law, com abertura interpretativa para os membros do Poder Judiciário sobre a lei e os efeitos que esta decisão produz.

$[\ldots]$.

Foi defendido que a simples tradução de determinadas expressões em nada contribuem para a correta compreensão das mesmas, sendo que, em alguns casos, vêm até mesmo a dificultar o correto entendimento daquilo que se tem na língua estrangeira. Não há mais como deixar de lado o estudo do que vem a ser a regra do stare decisis no Brasil, tendo em vista que, tanto nós, como àqueles sistemas de common law tem se tornado, a cada dia, mais híbridos do que de costume, chegando às vias de se pensar em trabalhar com um sistema misto de direito. (JOBIM, 2011, p. $115)$.
}

Neste sentido, os conceitos de direito comparado novamente voltaram a ter um significado importante, pois a comunicação entre os diversos sistemas jurídicos é cada dia mais palpável. 
Em meio a essas reflexões, a Primeira Emenda (Amendmentl) é uma parte da Declaração dos Direitos dos Estados Unidos. (NATIONAL ARCHIVES, 1789). A emenda $n^{\circ} 1$ qualifica a liberdade de religião, de expressão, de imprensa, de assembleia e de petição:

Congress shall make no law respecting an establishment of religion, or prohibiting the free exercise thereof; or abridging the freedom of speech, or of the press; or the right of the people peaceably to assemble, and to petition the Government for a redress of grievance ${ }^{3}$.

De todo modo, o referido dispositivo impede, textualmente, ao Congresso Americano de infringir seis direitos fundamentais:

a) Estabelecer uma religião oficial ou dar preferência a uma dada religião (a "Establishment Clause" da primeira emenda, que institui a separação entre a Igreja e o Estado);

b) Proibir o livre exercício da religião;

c) Limitar a liberdade de expressão;

d) Limitar a liberdade de imprensa;

e) Limitar o direito de livre associação pacífica e,

f) Limitar o direito de fazer petições ao governo com o intuito de reparar agravos.

Trata-se da mais recorrente das emendas constitucionais, enquanto elemento discursivo de representações sociais indicativas de liberdade de opinião. (WAGMAN, 1991). Do acima exposto, cabe destacar dois casos históricos da Suprema Corte Norte-Americana: caso Missouri Knights of the Klux Kux Khan v. Kansas City no qual garantiu-se a exibição de programas racistas em da liberdade de expressão e Texas v. Johnson, onde invalidou uma lei que proibia a profanação da bandeira nacional Estadunidense, com fulcro na primeira emenda, que garantia a liberdade de expressão.

\subsection{O Caso Missouri Knights Of The Klux Kux Khan V. Kansas City ${ }^{4}$}

Missouri Knights of the Klux Kux Khan v. Kansas City, caso que ocorreu em 1988, é elucidativo "de questões referentes à liberdade de expressão, no direito constitucional norteamericano". (ALDERMAN; KENNEDY, 1990, p. 123). Para Dennis Mahon, funcionário da

\footnotetext{
3 "O congresso não deverá fazer qualquer lei a respeito de um estabelecimento de religião, ou proibir o seu livre exercício; ou restringindo a liberdade de expressão, ou da imprensa; ou o direito das pessoas de se reunirem pacificamente, e de fazerem pedidos ao governo para que sejam feitas reparações de queixas".

5 The article "Freedom of Speech: Missouri Knights of the Ku Klux Klan v. Kansas City" both engage in conflicts pertaining to the First Amendment in the Bill of Rights.
}

TWA (dragão imperial do Missouri Knights of the KKK), ambicionava apresentar-se na Race and Reason, no canal 20, de Kansas City. "O programa era dirigido e apresentado por Tom Metzger do WAR (White Aryan Resistence). Temendo os 95\% de negros do bairro da estação de TV, os proprietários do veículo de comunicação exigiram que a produção devesse ser local. A KKK aceitou", e organizou o "programa Kansas City Kable. Emanuel Cleaver, pastor metodista negro", que conduziu o "movimento contra a KKK. Emanuel utilizou-se da "teoria 
do perigo real" (de Oliver Wendell Holmes) e com o leading case (de Eugene Debs) que em 1917 foi preso por ativismo socialista e por ser contrário à $1^{a}$ Guerra Mundial”. (ALDERMAN; KENNEDY, 1990, p. 123).

A Kansas City, em 16 de agosto de 1988, proclamou a "Resolução 62.555 que proibiu o acesso da população ao sinal da referida TV. Joanne Collins (que também era negra e membro do conselho municipal) votou contra. Com base na teoria do counterspeech", ambicionava desempenhar debate de grande porte na cidade. (ALDERMAN; KENNEDY, 1990, p. 123). "A $K K K$ protocolou ação contra a cidade de Kansas, questionando a Resolução 62.555. O município temia perder a ação. Se perdesse, pagaria 100.000 dólares em custas e honorários. A cidade vivia uma crise financeira", em pleno ano eleitoral. (ALDERMAN; KENNEDY, 1990, p. 123).

Em 13 de agosto de 1989, o conselho municipal reuniu-se, para deliberar a "propósito de eventual desistência da ação". A Suprema Corte norte-americana, em três de abril de 1990, reuniu-se "pela primeira vez em câmara plena. Por sete votos a três, decidiu-se que programas públicos seriam novamente autorizados, que a $K K K$ poderia apresentar seu programa e que assim garantia-se a liberdade de expressão". (ALDERMAN; KENNEDY, 1990, p. 123).

\subsection{O Caso Texas v. Johnson 5}

Segundo Godoy (2007, p. 22) "o caso Texas v. Johnson também é ilustrativo do conceito constitucional norte-americano relativo à liberdade de expressão".

Em 1984, Johnson queimou uma bandeira norte-americana, em sinal de protesto, em frente a um edifício em Dallas, no estado do Texas. Foi condenado por violar uma lei daquele estado, que tipificava como crime a profanação intencional de bandeira estadual ou nacional. O caso foi à Suprema Corte. (GODOY, 2007, p. 22).

A emenda $n^{\circ} 1$ envolvia a questão que recomendava que o Congresso "não fará lei

\footnotetext{
5 The article "Texas v. Johnson" both engage in conflicts pertaining to the First Amendment in the Bill of Rights.

relativa ao estabelecimento de religião ou proibindo o livre exercício desta; ou restringindo a liberdade de palavra ou de imprensa; ou o direito do povo reunir-se pacificamente e dirigir petições ao governo para a reparação de seus agravos". (IRONS, 1999, p. 468).

"A liberdade de expressão recebia entendimento constitucional" de amplo sentido, "como se observou no caso Missouri Knights of the Klux Klan v. Kansas City, quando se garantiu a exibição de programas racistas, na televisão, em nome da liberdade de expressão". A Suprema Corte definiu por cinco votos a quatro, "que a Constituição protege profanação à bandeira, como forma simbólica de expressão". (IRONS, 1999, p. 468, grifos do autor).
} 
De acordo com Irons (1999, p. 468) percebeu-se “que o governo não estaria autorizado a proibir ou restringir a expressão de uma ideia porque a sociedade achava essa ideia ofensiva ou desagradável”. Defendeu-se a combustão da bandeira como termo de "liberdade de expressão, como garantida na emenda n 1 (Bill of Rights) da constituição norteamericana".

\title{
3 O DIREITO DE MANIFESTAR NO BRASIL: NOVOS PARADIGMAS SOCIAIS
}

Como é possível verificar, modernamente, a soberania popular é exercida em regra por meio da democracia representativa, "sem, contudo descuidar-se da Democracia participativa" (BONAVIDES, 2001, p. 51), visto que são múltiplos os mecanismos de participação mais intensa do cidadão nas decisões governamentais (plebiscito, referendo, iniciativa popular), bem como são consagrados mecanismo que favorecem a existência de vários grupos de pressão (direito de associação, direito de reunião, direito de sindicalização, direito de manifestação).

Em meio a essas reflexões iniciais, cabe destacar o entendimento do Supremo Tribunal Federal-STF ${ }^{6}$ (BRASIL, 2013, p. 5) sobre o direito e limitações de manifestar em vias e logradouros públicos:

Com isso não se pretende afirmar que, sob o prisma jurídico-constitucional, o direito de reunião revista-se de caráter absoluto. Ao revés: o seu exercício pode encontrar-se

\footnotetext{
6 Trata-se de reclamação, aparelhada com pedido liminar, ajuizada pelo Sindicato Único dos Trabalhadores em Educação de Minas Gerais - SINDUTE, em face de ato do Tribunal de Justiça do Estado de Minas Gerais, que teria supostamente desafiado a autoridade da decisão proferida na Suprema Corte nos autos da ADI n ${ }^{\circ}$ 1.969-4/DF, rel. Min. Ricardo Lewandowski. Em síntese, aduz que a decisão reclamada, ao determinar liminarmente que o Reclamante se abstivesse de realizar manifestações em vias e logradouros públicos em qualquer parte do território estadual (Ação Cautelar $\mathrm{n}^{\circ}$ 1.0000.13.041148-1/000 ajuizada pelo Estado de Minas Gerais), restringiu substancialmente o conteúdo do direito fundamental de livre manifestação do pensamento (CRFB/88, art. $\left.5^{\circ}, \mathrm{IV}\right)$ e de reunião (CRFB/88, art. $\left.5^{\circ}, \mathrm{XVI}\right)$, nos balizamentos feitos pela Corte na ADI n ${ }^{\circ} 1.969-4 / \mathrm{DF}$, rel. Min. Ricardo Lewandowski.
}

\begin{abstract}
limitado em virtude da colisão com o conteúdo de outros bens jurídicos de mesma estatura constitucional. $\mathrm{Na}$ realidade, o próprio constituinte originário previu expressamente uma restrição ao exercício do direito de reunião, quando decretado o Estado de Defesa (CRFB/88, art. 136, § 1º I, alínea b). É inegável, entretanto, a virtude cívica de movimentos sociais espontâneos que conclamem a participação ativa dos cidadãos na vida pública, de sorte a estimular a reflexão acerca de temas caros à ordem jurídica, política e econômica nacional. A democracia, longe de exercitar-se apenas e tão somente nas urnas, durante os pleitos eleitorais, pode e deve ser vivida contínua e ativamente pelo povo, por meio do debate, da crítica e da manifestação em torno de objetivos comuns (Reclamação 15887/MG).
\end{abstract}

Neste diapasão, não cabe ao Poder Executivo (e Forças Policiais) restringir o direito de manifestar, ressalvados os casos previstos na Constituição Federal/88. Destarte, todos podem reunir-se pacificamente, sem armas, em locais abertos ao público, independentemente 
de autorização, desde que não frustrem outra reunião anteriormente convocada para o mesmo local, sendo apenas exigido prévio aviso à autoridade competente.

No caso das manifestações pela descriminalização da maconha, a liberdade de reunião pode ser vista como instrumento da livre manifestação de pensamento, aí incluído o direito de protestar.

O direito de manifestação pressupõe um agrupamento de pessoas (elemento subjetivo) e deve ostentar um mínimo de coordenação (elemento formal). A aglomeração deve ser o resultado de uma convocação prévia e integrá-la conscientemente. As pessoas que dela participam comungam de um fim comum - que pode ter cunho político, religioso, artístico ou filosófico (elemento teleológico).

Ao longo da história, as manifestações populares reivindicaram novos direitos sociais, valores e objetivos em torno dos quais as instituições da sociedade se transformaram a fim de representar esses valores, criando novas normas para organizar a vida social. Nessa perspectiva, um novo fenômeno marcou as manifestações da "Marcha da maconha": a descriminalização da maconha; e as jornadas de junho de 2013 marcaram o descrédito nas instituições partidárias.

\subsection{O caso da descriminalização da maconha pelo STF}

Pode-se dizer que, no espaço público brasileiro, assim como em diversos outros países, discute-se cada vez mais um tema de inequívoco interesse social: a criminalização das drogas ${ }^{7}$. Em tão importante debate público, há um lado que defende a legitimidade e a

\footnotetext{
${ }^{7}$ Fundamentação de arguição de descumprimento de preceito fundamental (ADPF) 187, que foi ajuizada pela Procuradora-Geral da República em exercício, Dra. Deborah Macedo Duprat de Britto Pereira.
}

eficiência da estratégia criminal no combate às drogas; enquanto outro pugna pela legalização, ou, pelo menos, de algumas delas.

Neste diapasão, muitos ressaltaram que a liberdade de pensamento nestas manifestações somente pode ser proibida quando for dirigida a incitar ou provocar ações ilegais e iminentes. Droga proibida, a maconha está no centro de um debate internacional acerca da existência ou não de algum sentido em se manter o combate ao tráfico nos moldes que se utiliza há décadas.

Estadistas de prestígio sustentam a necessidade de mudar de atitude em relação aos narcotraficantes, porque as drogas têm sido as vencedoras, até o momento. Nos demais, o que se vê é a corrupção dos meios policiais, o crescente contingente de jovens dependentes que vivem à beira da marginalidade, as clínicas de recuperação cada vez mais solicitadas. 
A discussão no país, ao menos neste estágio em que ainda se luta contra "tabus", preconceitos e desinformação, se desenrola em torno da descriminalização de certas drogas. $\mathrm{Na}$ agenda, temas centrais como a fragilização do tráfico, a distinção, para efeitos legais e de saúde, entre usuário e traficante, bem como a mudança de paradigma na política nacional de drogas, tratando o problema como questão de saúde pública e não restrita a seus aspectos puramente policiais.

Algo muito frequente nas sociedades modernas são as pesquisas de opinião pública, feitas com o intuito de averiguar o grau de aprovação de políticas sociais de um governo (legitimidade). Com a finalidade de levantar informações sobre a opinião pública, a pesquisa Ibope/Estado/Globo divulgou que 79\% dos eleitores brasileiros são contra a descriminalização da maconha, e somente $17 \%$ a favor. (BRAMATTI; TOLEDO, 2014).

MORAES (2006, p. 260) destaca que o direito de debater certas ideias em reuniões é um princípio basilar:

O direito de reunião configura-se com um dos princípios basilares de um Estado
Democrático, sendo um direito público subjetivo de grande abrangência, pois não se
compreenderia a liberdade de reuniões sem que os participantes pudessem discutir,
tendo que limitar-se apenas ao direito de ouvir, quando se sabe que o direito reunião
compreende não só direito de organizá-la e convocá-la, como também o de total
participação ativa.

A discussão sobre a "Marcha da Maconha" chegou ao STF em junho de 2009, quando a vice-procuradora-geral da República Deborah Duprat ajuizou a Arguição de Descumprimento de Preceito Fundamental (ADPF) 187. "Na ação, a procuradora indica que a proibição judicial das marchas a favor da maconha e de outros entorpecentes tem sido baseada em interpretação errada do Código Penal”. (BRANDT, 2011).

Após análise, o voto do relator da ADPF 187 (ministro Celso de Mello), foi seguido integralmente pelos colegas. Pela decisão tomada no julgamento, o artigo 287 do Código Penal 8 deve ser interpretado conforme a Constituição de forma a não impedir manifestações públicas em defesa da legalização de drogas. (SUPREMO TRIBUNAL FEDERAL, 2011).

Segundo o decano-relator da Corte, a "marcha da maconha" é um movimento social espontâneo que reivindica, por meio da livre manifestação do pensamento, "a possibilidade da discussão democrática do modelo proibicionista (do consumo de drogas) e dos efeitos que (esse modelo) produziu em termos de incremento da violência”. (SUPREMO TRIBUNAL FEDERAL, 2011).

Celso de Mello explicou que "a mera proposta de descriminalização de determinado ilícito penal não se confunde com o ato de incitação à prática do delito nem com o de apologia de fato criminoso". (SUPREMO TRIBUNAL FEDERAL, 2011).

Ponderou que o "debate sobre abolição penal de determinadas condutas puníveis pode ser realizado de forma racional, com respeito entre interlocutores, ainda que a ideia, para a 
maioria, possa ser eventualmente considerada estranha, extravagante, inaceitável ou perigosa". (SUPREMO TRIBUNAL FEDERAL, 2011).

Ficaram estabelecidos, pelo Supremo Tribunal Federal (2011), ainda, parâmetros para a realização das referidas manifestações:

a) Que elas devem ser pacíficas, sem uso de armas e incitação à violência;

b) Devem ser previamente noticiadas às autoridades públicas, inclusive com informações como data, horário, local e objetivo do evento;

c) Imperioso que não haja incitação, incentivo ou estímulo ao consumo de entorpecentes durante a marcha;

d) Não pode haver consumo de entorpecentes no evento.

Ficou consignado que as decisões do Poder Judiciário coibindo a realização de atos públicos favoráveis à legalização das drogas, unicamente porque usar maconha é ilegal, são incombináveis com a garantia constitucional da liberdade de expressão. Pode-se dizer que mesmo quando a concordância "coletiva se revela improvável, a simples possibilidade de proclamar publicamente certas ideias corresponde ao ideal de realização pessoal e de demarcação do campo da individualidade”. (SUPREMO TRIBUNAL FEDERAL, 2011).

\footnotetext{
${ }^{8}$ O dispositivo tipifica como crime fazer apologia de "fato criminoso" ou de "autor do crime".
}

Desse ponto de vista, a liberdade de expressão é um fator relevante na construção de novos paradigmas sociais e no resguardo da democracia, cujo pressuposto indispensável é o pluralismo ideológico. (SUPREMO TRIBUNAL FEDERAL, 2011).

\section{MOMENTO HISTÓRICO NO BRASIL: AS JORNADAS POPULARES DE 2013}

Pode-se dizer que não é a norma que muda a sociedade, é a sociedade que muda as normas. Para um magistrado treinado no positivismo jurídico irá exigir-se mais estudo e mais tempo para uma decisão que aceite uma concepção de pluralismo jurídico.

Boaventura de Sousa Santos, ao realizar um trabalho empírico em uma comunidade no Rio de Janeiro, batizada por ele de "Pasárgada", assim definiu a situação de pluralismo jurídico:

Existe uma situação de pluralismo jurídico onde o espaço geopolítico vigora (oficialmente ou não) mais de uma ordem jurídica. Esta pluralidade normativa pode ter uma fundamentação econômica, rácica, profissional ou outra; pode corresponder a um período de ruptura social como, por exemplo, um período de transformação revolucionária; ou pode ainda resultar, como no caso de Pasárgada, da conformação 
específica do conflito de classes numa área determinada da reprodução social- neste caso, a habitação (SANTOS, 1993, p. 42).

Na obra As Regras do Método Sociológico, Émile Durkheim (1984, p. 11) determina "sua metodologia de análise e define o fato social como objeto de estudo da sociologia, ressaltando o papel dessa ciência na sociedade contemporânea e na relação entre indivíduo e sociedade".

Entende que a consciência coletiva se torna fora do indivíduo, possuindo poder de coagir as consequências individuais. Neste sentido, é significativa a noção do fato social (consciência coletiva) elaborada por Durkheim (1984, p. 11):

\footnotetext{
É fato social toda maneira de agir, fixa ou não, suscetível de exercer sobre o individuo uma coerção exterior; ou então ainda, que é igual na extensão de uma sociedade dada, aparentando uma existência própria, independente das manifestações individuais que possa ter.
}

Existem diversas formas de se determinar um fato social, e uma delas é por meio da análise empírica. O fato social, conforme Emile Durkheim, deve representar "um certo estado de espírito coletivo".

Com o objetivo de levantar informações sobre a diversidade de matizes ideológicas e o perfil dos participantes das manifestações que aconteceram no Brasil, o IBOPE Inteligência, em oito capitais brasileiras, ouviu 2002 pessoas durante os protestos de junho de 2013.

Conforme pesquisa do Ibope Inteligência (2013), “a maioria dos manifestantes dizia não se sentir representada por partido (89\%) ou político brasileiro (83\%)", ou seja apartidários. Quando questionados sobre quais as reivindicações que os levaram às ruas, 38\% dos entrevistados apontaram a questão do transporte público como primeiro motivo de mobilização. (IBOPE INTELIGÊNCIA, 2013).

Quando considerada a soma de todas as questões mencionadas pelos manifestantes, $65 \%$ reivindicavam mudanças no atual ambiente político, $54 \%$ no transporte público e $37 \%$ na área da saúde. (IBOPE INTELIGÊNCIA, 2013).

Neste contexto, as manifestações populares ocorridas no Brasil em junho de 2013 representam um novo marco histórico na democracia brasileira. Ainda que esses movimentos já estivessem presentes em outras roupagens, a novidade em 2013, e o que tornou as manifestações de fato impactantes é que:

a violência entra em cena nas manifestações de rua por duas vias: a policial, várias vezes de forma brutal, tratando os manifestantes tal como enfrentam uma ocupação de marginais em uma favela, com todo aparato da repressão; e a violência no comportamento de alas dos manifestantes, apresentada como violência simbólica, como tática do movimento (Black Blocs). (GOHN, 2014).

Segundo Boaventura de Sousa Santos, as manifestações populares ocorridas no Brasil em junho de 2013 marcaram um novo cenário histórico do país, devido a sua originalidade quanto à diversidade ideológica, a multiplicidade de interesses antagônicos dos diversos grupos 
sociais participantes e um movimento de bandeira antipartidarista. (XAVIER; ESPÍNOLA; et al, 2014).

Acrescenta o sociólogo português que a onda de indignação que tomou as ruas do país tem como "pano de fundo" as mudanças vividas pela sociedade brasileira nas últimas décadas e a classe média, afirma, cresceu e com ela as demandas dos cidadãos por melhores serviços públicos ganharam força. (XAVIER; ESPÍNOLA; et al, 2014).

Neste contexto, um novo fenômeno social marcou as manifestações de junho de 2013 no Brasil: o ceticismo em relação às instituições partidárias.

\section{COMO SURGE A VIOLÊNCIA NAS MANIFESTAÇÕES: ATUAÇÃO DAS FORÇAS POLICIAIS}

As manifestações de violência física (exercício de força e coação) podem ser aquelas que são aceitas pela maioria da população (violência legítima) e aquelas que são consideradas injustas, abusivas, sem justificação (violências ilegítimas).

Hoje pode ser legítima somente a violência física que provém do Estado (ação policial) ou é autorizada por ele (legítima defesa). Não é difícil constatar que o direito tem uma importância particularmente grande para o processo de legitimação do poder político.

O direito é um instrumento que permite legitimar o poder de violência do Estado. A existência do Direito e o respeito a ele oferecem ao cidadão uma "sensação de segurança".

O Direito lhe permite saber o que deve fazer (certeza) e o que pode esperar dos outros (previsibilidade), ou seja, lhe permite organizar a sua vida e conseguir uma estabilidade (reduzir a complexidade $\left.{ }^{9}\right)$.

Durante os protestos de junho de 2013, policiais e jovens manifestantes protagonizaram fortes cenas de conflito. A vontade de transgredir leis, regras e normas é um impulso comum entre os adolescentes.

Em diversas capitais as mobilizações extrapolaram a capacidade organizativa dos grupos e movimentos que as desencadearam, criando movimentos multicêntricos onde cabem diversas estratégias, táticas e narrativas mobilizadoras.

Numa análise social, algumas "transgressões" são consideradas pelos jovens como benéficas. 
Para o jovem moderno, o ato de transgredir pode (se) provar que é alguém, que tem valor, que dispõe de uma existência própria, que é (quase) independente, produzindo assim um bálsamo para suas feridas narcísicas.

A inquietação juvenil é vista como sinal de problema, de rejeição da família e de busca da emancipação.

Sua tendência comum de cometer pequenas transgressões, contestando pais e desafiando autoridades, não somente faz parte do processo de crescimento, como também é necessária para retomada da autoafirmação e da autoestima abaladas.

Neste contexto, para jovens entediados que experimentaram todas as formas de lazer só parece restar a violência como alternativa de diversão.

Assim, o sentimento de impunidade e a tirania das vontades individuais são os ingredientes que, somados, tendem a dar ao grupo uma sensação de confiança e onipotência.

${ }^{9}$ Termo usado por Niklas Luhmann na teoria do "sistema autopoiético".

Fazer parte de uma gangue fortalece a pessoa que necessita ser reconhecida ou valorizada, o que muitas vezes não acontece no lar, na rua ou na escola.

A socióloga Maria da Glória Gohn (2014, p. 433) destaca que:

\begin{abstract}
Nas manifestações de 2013, pode-se indagar se ela ressurge como nova forma de luta social ou internacionalização de formas de protesto. $O$ fato novo é a violência ser apresentada e justificada por essas alas dos manifestantes como forma predominante da ação no protesto, e esse fato reforça a hipótese de mudança na composição e no caráter dos movimentos nas ruas. A violência performática como norma de conduta é um registro de formas de movimentos de protestos internacionais deste novo século. As manifestações iniciadas em Junho, em São Paulo, foram caracterizadas, inicialmente, na mídia e por muitos políticos, como atos de "vândalos".
\end{abstract}

Diante das graves ocorrências, o uso indiscriminado da força por parte da polícia passa a ser alvo de discussões e questiona-se a sua capacidade em garantir a segurança.

A violência generalizada nas manifestações ocorridas em Junho de 2013 afastou parte da sociedade e contribuiu para o enfraquecimento dos ativistas.

Howard Becker (2008) estudioso da Sociologia do desvio (Sociology of Deviance) utiliza a expressão “outsider" para qualificar as pessoas que desviam do comportamento padrão socialmente esperado. No entanto, esclarece que o desvio é relativo, pois dependerá do grupo social e dos atores sociais à que estão ligados. A noção de desvio é uma caracterização social de qualquer comportamento fora do padrão em diferentes contextos.

Para Becker (2008, p. 27). "Desvio não é uma qualidade que reside no próprio comportamento, mas na interação entre a pessoa que comete um ato e aquelas que reagem a ele". Como as sociedades complexas são sempre compostas por diversos grupos, imposições 
de regras e rotulações de atos e pessoas, elas envolvem também conflitos e divergências acerca de definições: "aquele que infringe a regra pode pensar que seus juízes são outsiders". (BECKER, 2008, p.15).

\section{CONSIDERAÇÕES FINAIS}

Os direitos humanos, historicamente, foram conquistados em oposição à força estatal, de forma que, no Estado Democrático de Direito, as forças polícias devem usar apenas os meios necessários e suficientes para manter a paz social e fazer prevalecer à ordem pública.

Por uma interpretação sistemática, o princípio democrático exprime fundamentalmente a exigência da integral participação de todos e de cada uma das pessoas na vida política do país, a fim de garantir-se o respeito à livre manifestação.

O direito de manifestação liga-se intimamente à liberdade de pensamento e ao sistema democrático de governo.

No caso da "marcha da maconha", o Poder Público não têm como saber, de antemão, se os participantes estarão no protesto para consumir substâncias ilícitas. Se isso vier a ocorrer,

devem ser tratados de acordo com a lei vigente no país, mas a mera possibilidade não pode servir de base para a proibição de manifestação legítima a favor de uma ideia, de um novo paradigma.

Nessa mesma perspectiva, é presunção dizer que a realização das jornadas de junho de 2013 e a "marcha da maconha" constitui ato de incitação à prática de "delito" e nem com o de apologia a "fato criminoso".

Pode-se dizer que o texto constitucional consagrou a liberdade de manifestação do pensamento como um dos direitos fundamentais do indivíduo ${ }^{10}$.

Não se trata, porém, de barreira para que o Judiciário estipule, no caso concreto ou concentrado, os limites da livre manifestação do pensamento (racismo, homofobia, religião, crueldade de animais). Está expresso no artigo 5 , Inciso XXXV, da Constituição de 1988: "a lei não excluirá da apreciação do Poder Judiciário lesão ou ameaça a direito".

Assim, quando dois interesses estiverem em conflito, caberá ao órgão judicante decidir, dentro dos novos paradigmas sociais, qual deles deverá prevalecer.

Neste estará cumprindo a Constituição, porque censura prévia não se confunde com controle jurisdicional de legalidade; e o Judiciário tem o poder-dever, cautelar ou definitivo, de intervir, sempre que houver lesão ou ameaça de lesão a um direito. 
Essas normas procedimentais - as "regras do jogo" - devem ser amparadas por um sólido sistema de direitos fundamentais.

Tais direitos asseguram a participação e a contribuição de todos os cidadãos para o exercício da democracia. Representam a estrutura de sustentação e de eficácia do princípio democrático.

${ }^{10}$ Art. 5, inc. XVI da Constituição Federal de 1988.

Nesse contexto, assume relevância o direito fundamental da liberdade de expressão, que se desdobra em diferentes facetas: direito de discurso, direito de opinião, direito de imprensa, direito à informação e proibição da censura.

Um país não pode denominar-se uma democracia até que os cidadãos possam expressar-se sem medo e sem repressão policial.

Esse princípio está contido - no direito comparado, na Primeira Emenda à Constituição norte-americana e cabe à Suprema Corte garantir os direitos de livre manifestação, imprensa, crença e associação.

É axiomático que numa sociedade global fragmentada, diante das inúmeras situações em que se apresenta, com características de pluralismo jurídico, que se requeira o livre fluxo de ideias e a proteção daqueles que queiram contribuir para o bem comum. (SANTOS, 2007).

Para os ministros do Supremo Tribunal Federal/STF, os direitos constitucionais de reunião e de livre expressão do pensamento garantem a realização das "Marcha da maconha".

Ainda que o presente estudo tenha chegado a um entendimento, o tema não está esgotado, podendo no futuro próximo se chegar a outros juízos, diante das inúmeras situações em que a sociedade se apresenta e de clara efetivação de novos paradigmas sociais. 


\section{REFERÊNCIAS}

ALDERMAN, Ellen; KENNEDY, Caroline. In our defense: the Bill of Rights in action. New York: Morrow, 1990.

ARENDT, Hannah. A condição humana. 11. ed. Rio de Janeiro, Forense Universitária, 2010.

BECKER, Howard Saul. Outsiders: estudos de sociologia do desvio. Tradução Maria Luiz X. de A. Borges. Rio de Janeiro: Jorge Zahar, 2008. 231 p. Tradução de: Outsiders: studies in the sociology of deviance.

BONAVIDES, Paulo. Teoria constitucional da democracia participativa: por um direito constitucional de luta e resistência, por uma nova hermenêutica, por uma repolitização da legitimidade. São Paulo: Malheiros, 2001.

BRAMATTI, Daniel; TOLEDO, José Roberto de. Ibope: Quase 80\% são contra legalizar maconha e aborto. Estadão - Política, São Paulo, 04 set. 2014. Disponível em:

$<$ http://politica.estadao.com.br/noticias/geral,ibope-quase-80-sao-contra-legalizar-maconha-eaborto,1554665>. Acesso em 26 jan. 2016.

BRANDT, Fábio. Maioria do STF libera realização da Marcha da Maconha. UOL Notícias Cotidiano, Brasília, 15 jun. 2011. Disponível em:

$<$ http://noticias.uol.com.br/cotidiano/ultimas-noticias/2011/06/15/maioria-do-stf-vota-afavor-da-liberacao-da-marcha-da-maconha.htm>. Acesso em: 26 jan. 2016.

BRASIL. Constituição (1988). Constituição da República Federativa do Brasil de 1988. Disponível em: <http://www.planalto.gov.br/ccivil_03/constituicao/>. Acesso em: 24 jan. 2015.

BRASIL. Supremo Tribunal Federal. Reclamação 15.887 Minas Gerais. Reclamante: Sindicato Único dos Trabalhadores em Educação de Minas Gerais - SINDUTE/MG. Reclamado: Tribunal de Justiça do Estado de Minas Gerais. Relator Ministro Luiz Fux. Brasília, 19 de junho de 2013. Disponível em: <www.stf.jus.br/arquivo/cms/noticianoticiastf/anexo/rcl_15887.pdf>. Acesso em: 2 jul. 2015.

COHEN, Marina. Com Marcha da Maconha programada para o fim de semana, organização internacional Leap, formada por policiais e membros da Justiça, prega a legalização de todas as drogas. O Globo, Rio de Janeiro, 06 maio 2011. Disponível em:

<http://oglobo.globo.com/cultura/megazine/com-marcha-da-maconha-programada-para-fimde-semana-organizacao-internacional-leap-formada-por-policiais-membros-da-justicaprega-legalizacao-de-todas-as-drogas-2773760>. Acesso em: 26 jun. 2015.

DURKHEIM, Émile. As regras do método sociológico. Lisboa: Presença, 1984.

FRANK, André Gunder; FUENTES, Marta. Dez teses acerca dos movimentos sociais. Lua Nova: Revista de Cultura e Política, São Paulo, n. 17, p. 19-48, jun. 1989. Disponível em: $<$ http://www.scielo.br/scielo.php?script=sci_arttext\&pid=S0102-

64451989000200003\&lng=en\&nrm=iso>. Acesso em: 30 mar. 2016. 
GODOY, Arnaldo Sampaio de Moraes. Direito comparado: introdução ao direito constitucional norte-americano. Revista Jus Navigandi, Teresina, a. 12, n. 1515, 25 ago. 2007. Disponível em: <https://jus.com.br/artigos/10282>. Acesso em: 26 jun. 2016.

GOHN, Maria da Glória. A sociedade brasileira em movimento: vozes das ruas e seus ecos políticos e sociais. Caderno CRH, Salvador, v. 27, n. 71, p. 431-441, ago. 2014. Disponível em: <http://www.scielo.br/scielo.php?script=sci_arttext\&pid=S010349792014000200013\&lng=en\&nrm=iso>. Acesso em: 30 mar. 2016.

IBOPE INTELIGÊNCIA. 89\% dos manifestantes não se sentem representados por partidos. São Paulo, 25 jun. 2013. Disponível em:

$<\mathrm{http}$ ://www.ibopeinteligencia.com/noticias-e-pesquisas/89-dos-manifestantes-nao-sesentem-representados-por-partidos/>. Acesso em: 20 jan. 2016.

IRONS, Peter. A people's history of the Supreme Court. New York: Penguin Books, 1999.

JOBIM, Marco Félix. Entendendo a nomenclatura dos precedentes. Direito e Democracia Revista de Ciências Jurídicas. ULBRA. Canoas, v. 12, n. 2, jul./dez. 2011. Disponível em: <http://www.ulbra.br/upload/e410caee5767f5ea4e859b3264d7ca64.pdf >. Acesso em: 02 jul. 2015.

MARSHALL, T. H.. Cidadania, classe social e status. Tradução Meton Porto Gadelha. Rio de Janeiro: Jorge Zahar, 1967. Tradução de: Sociology at the crossroads and other essays.

MORAES, Alexandre de. Constituição do Brasil interpretada e legislação constitucional: atualizada até a EC nº 52/06. 6. ed. São Paulo: Atlas, 2006.

NATIONAL ARCHIVES. Bill of Rights (1789). United States Bill of Rights. Disponível em: $<$ http://www.archives.gov/exhibits/charters/bill_of_rights_transcript.html>. Acesso em: 26 jun. 2015.

SANTOS, Boaventura de Sousa. A crítica da razão indolente: contra o desperdício da experiência. São Paulo: Cortez, 2007.

SANTOS, Boaventura de Sousa. Nota sobre a história jurídico-social de Pasárgada. In: SOUSA, José Gerardo (Org.). Introdução crítica ao direito. 4. ed. Brasília: Universidade de Brasília, 1993.

SUPREMO TRIBUNAL FEDERAL. STF libera “marcha da maconha". Brasília, 15 jun. 2011. Disponível em: <http://www.stf.jus.br/portal/cms/verNoticiaDetalhe.asp?idConteudo=1 82124>. Acesso em: 26 jan. 2016.

WAGMAN, Robert J. The first amendment book. New York: Pharos Books, 1991.

XAVIER, Gabriela Costa; ESPÍNOLA, Thaísa Ferreira Amaral Gomes et al. O direito de manifestação no Brasil. Revista Jus Navigandi, Teresina, ano 19, n. 4005, 19 jun. 2014. Disponível em: <https://jus.com.br/artigos/29506>. Acesso em: 28 jan. 2016. 